Online Perspectives Journal: Exact \& Engineering Proceedings of the 5th Research \& Development PROVIC/PIBIC Seminar 2nd CNPq Scientific Initiation Meeting, Vol. 10, No 29, Supplement, 2020

\title{
Comportamento em compressão de micocompósitos obtidos por diferentes substratos e fungos
}

\author{
Nahura Pessanha Silva ${ }^{1}$, Bárbara Ferreira de Oliveira², Glória Andreia Ferreira Hernández ${ }^{3}$, \\ Luana Pinto de Souza Tavares ${ }^{3}$, Vicente Mussi-Dias ${ }^{4}$, Maria das Graças Machado Freire ${ }^{5}$ \\ (1) PROVIC/ISECENSA Voluntary Scientific Research Student - Civil Engineering Course; (2) Collaborative Researcher - LAPSIM/ISECENSA; (3) \\ Technical-assistant in Chemistry - LAQUIBIO/ISECENSA; (4) Collaborative Researcher - LAQUIBIO/ISECENSA; (5) Guiding Professor - \\ LAQUIBIO - Research and Post-Graduation Center (CPPG) / CENSA-ISECENSA Superior Education Institutes, Rua Salvador Correa, 139, Centro, \\ Campos dos Goytacazes, RJ, Brazil
}

Observa-se atualmente crescente utilização de resíduos agroindustriais para minimizar o processo de decomposição anaeróbica, que provoca a emissão de metano, um dos mais importantes gases de efeito estufa. Várias estratégias têm sido desenvolvidas para o manejo de parte das vastas quantidades geradas de resíduos lignocelulósicos, incluindo a utilização de micro-organismos degradadores de matéria orgânica. Os fungos basidiomicetos, também conhecidos como cogumelos e orelhas de pau, desempenham papel fundamental na ciclagem de nutrientes na natureza, principalmente no ciclo do carbono, na medida que são excelentes degradadores de lignina, o segundo biopolímero mais abundante sobre a Terra. O objetivo deste projeto será avaliar o potencial de fungos de podridão branca na obtenção de um compósito à base de resíduos orgânicos que represente uma alternativa para a geração de produtos sustentáveis. Serão testados diversos substratos formulados a base de serragem de madeira, casca e/ou borra de café e farelos de grãos variando a porcentagem dos materiais. Os substratos estéreis prémiceliados serão acondicionados em moldes e incubados a $25{ }^{0} \mathrm{C}$ durante 15 dias. Após este período, o compósito obtido será submetido à temperatura de $80^{\circ} \mathrm{C}$ por 12 horas para eliminar o desenvolvimento do fungo. A relação entre a composição química dos substratos e as propriedades mecânicas dos compósitos resultantes serão analisadas através de ensaios de compressão. Espera-se que o micocompósito obtido, totalmente natural e biodegradável, seja um representante da economia circular, na qual os produtos além de duráveis possibilitem a geração de novos resíduos recicláveis ao final de sua vida útil.

Palavras-chave: Biorremediação . Micélio . Sustentabilidade .

Instituição de Fomento: ISECENSA. 